\title{
Polymer action on alkali-silica reaction in cement mortar
}

\author{
João Feiteira *, Maria S. Ribeiro *,1 \\ Concrete Division of Materials Department, LNEC, Laboratório Nacional de Engenharia Civil, Avenida do Brasil 101, 1700-066 Lisboa, Portugal
}

\section{A R T I C L E I N F O}

\section{Article history:}

Received 6 September 2011

Accepted 25 September 2012

\section{Keywords:}

SEM (B)

Microcracking (B)

Alkali-aggregate reaction $(\mathrm{C})$

Polymers (D)

Mortar (E)

\begin{abstract}
A B S T R A C T
Due to the improvement of several properties, such as lower water absorption and increasing resistance to microcracking, polymer modification of mortar and concrete potentially leads to an inhibiting effect on alkalisilica reaction (ASR). In this study, polymer-cement mortars (PCMs) were subjected to accelerated alkali reactivity tests and their performance compared to that of an unmodified cement mortar (CM). Expansion of PCMs was overall higher, but SEM observations revealed apparent lower microcracking intensity of the cement paste, compared to the unmodified CM. Subsequent stiffness damage tests (SDTs) quantified the existing damage after alkali reactivity tests and confirmed the lower microcracking intensity in PCMs.
\end{abstract}

(c) 2012 Elsevier Ltd. All rights reserved.

\section{Introduction}

The alkali-silica reaction (ASR) has been responsible for premature concrete degradation in more than 40 countries all over the world [1]. This phenomenon consists of a chemical reaction between the hydroxyl $\left(\mathrm{OH}^{-}\right)$, sodium $\left(\mathrm{Na}^{+}\right)$, potassium $\left(\mathrm{K}^{+}\right)$and calcium $\left(\mathrm{Ca}^{2+}\right)$ ions present in the highly alkaline pore solution of concrete and poorly crystallized silica minerals present in some aggregates. This reaction progressively transforms silica minerals into an alkalisilica gel with hygroscopic properties, which can expand due to hydration and crack the aggregate and surrounding cement paste [2].

Preventing measures have been studied and used whenever potentially reactive aggregates cannot be avoided. Besides limiting the alkali content in concrete, supplementary cementitious materials (SCMs) and lithium compounds have been shown to have a reducing effect on ASR-related expansion.

The main inhibiting mechanism of SCMs is the reduction of $\mathrm{Na}^{+}$, $\mathrm{K}^{+}$and $\mathrm{OH}^{-}$ion concentration in the pore solution [3], which can be partially justified by the alkali dilution in concrete as result of the replacement of part of the cement with SCMs of lower alkali content. However, other inhibiting mechanisms exist, as even SCMs with higher alkali content than the replaced cement can lead to the reduction of ASR-related expansion [4].

As the $\mathrm{Ca}(\mathrm{OH})_{2}$ content of concrete has been linked to an increased potential for ASR-related expansion, the reduced $\mathrm{Ca}(\mathrm{OH})_{2}$ content of concrete resulting from the pozzolanic reaction set off by SCMs is also regarded as another inhibition mechanism. However, it

\footnotetext{
* Corresponding authors. Tel.: + 351218443964.

E-mail addresses: jfeiteira@Inec.pt (J. Feiteira), sribeiro@lnec.pt (M.S. Ribeiro).

1 Tel.: + 351218443226
}

has been shown that $\mathrm{Ca}(\mathrm{OH})_{2}$ reduction is not a significant inhibiting mechanism of SCMs unless $\mathrm{Ca}(\mathrm{OH})_{2}$ is almost completely deleted [5]. Nevertheless, several authors [2,6-8] support that the calcium-rich ASR gel found in cement paste with available $\mathrm{Ca}(\mathrm{OH})_{2}$ is responsible for the creation of a reaction rim around reactive aggregate particles, with different models being proposed to explain the link between the observed reaction rim and the potential for higher ASR-related expansion. There is also evidence that the reduced $\mathrm{Ca} / \mathrm{Si}$ ratio of the CSHs formed in the presence of SCMs results in an increased capacity to accommodate alkalis and further reduce the $\mathrm{OH}^{-}$content of the pore solution, thus reducing ASR-related expansion [9].

Lithium salts have also been reported to have a reducing effect in ASR-related expansion mainly through modification of the microstructure [10] and chemical composition of the ASR gel [11].

Polymers have long been used for modification of cementitious materials, more notably for water absorption reduction and adhesion improvement of concrete repair mortars and cementitious coatings, but polymer modification of concrete has also been studied for its improved durability [12-14].

Polymers can improve properties in concrete with potential reducing effects on ASR-related expansion and damage, such as lower water absorption, reduced ionic permeability of the polymer-cement co-matrix [15] and higher tensile strength and ductility. Due to their higher tensile strength and ductility, the resistance to microcracking of polymer-modified cement mortar (PCM) can be higher than that of unmodified CMs [16-18]. The refinement of the ITZ [19], the improved adhesion between aggregates and cement paste and the bridging capabilities of polymer film on the onset of microcracking explain the higher tensile strength and ductility of PCMs. Schorn et al. [20] were able to directly observe the polymer bridging of microcracks on small specimens attached to a special loading device inside the chamber of an environmental scanning electron microscope. 
The complex process of mutual influence of cement hydration and polymer film formation in PCMs and polymer-modified concrete also modifies both the morphology and availability of certain cement hydration products. Due to the interaction between $\mathrm{Ca}^{2+}$ cations present in the pore solution of cement paste and both the carboxylate groups of polymers $[15,21,22]$ and surfactants used in polymer additions [23], $\mathrm{Ca}(\mathrm{OH})_{2}$ quantity is reduced, particularly at the interfacial transition zone (ITZ), during early ages of cement hydration and for polymer to cement weight ratios above 10\% [15,24,25]. Depending on their nature and dosage, polymers may also influence the morphology of $\mathrm{Ca}(\mathrm{OH})_{2}$ crystals, which are also more frequently found growing in pores [26-29].

Some of the modifications induced by polymer additions discussed show similarities with ASR inhibiting mechanisms of SCMs and lithium salts. Thus, while there are reasons to believe that the properties of mortars and concrete that polymers have been shown to modify might have a reducing effect in ASR-related expansion, the few results reported in the literature $[10,30]$ are inconclusive, using distinct test methods (which render comparison difficult) and covering only a limited range of the available polymer types. Ohama et al. [10] reported a lower expansion of a styrene-butadiene modified mortar only for $\mathrm{P} / \mathrm{C}$ higher than $10 \%$. Saccani and Motori [30] reported that epoxy-modified mortar with either $10 \%$ or $20 \% \mathrm{P} / \mathrm{C}$ significantly reduced expansion almost to the same level of comparable unmodified cement mortar with sound aggregate. Additionally, neither of the works cited assessed the damage resulting from ASR-related expansion.

This study presents the results of an assessment of the influence of styrene-butadiene, acrylic-styrene and epoxy polymer additions on ASR in cement mortars along with an analysis of their potentially intervening mechanisms.

\section{Materials}

\subsection{Aggregates}

Crushed pebblestone with original minimum (d) and maximum (D) dimensions of respectively $5.6 \mathrm{~mm}$ and $11.2 \mathrm{~mm}$ was used. The pebblestone aggregate was crushed again to obtain the grading specified in the ASTM C 1260 alkali reactivity test. After crushing and combining the different grades in the required proportions, the properties of the resulting aggregate were determined according to EN 933-1 and an ASTM C 1260 test was conducted to assess its alkali reactivity. The results of these tests are shown in Table 1 . The alkali reactivity of the pebblestone was confirmed, as the expansion at 14 days was higher than the $0.20 \%$ lower limit for reactive aggregates specified in ASTM C 1260. Fig. 1 shows the granulometry curve of the aggregates used in this study.

\subsection{Cement}

A CEM I 42.5 R Portland cement was used in this study. The chemical and mechanical properties of this cement are listed in Table 2.

\subsection{Polymer additions}

Commercially available styrene-butadiene (SB 1 and SB 2) and acrylic-styrene (AS 1) dispersions and a two-component (diglycidil ether of bisphenol-A and an aliphatic amine hardener) aqueous epoxy (EP) were selected for cement mortar modification in this

Table 1

Aggregate properties.

\begin{tabular}{lllll}
\hline Aggregate & $\mathrm{d}(\mathrm{mm})$ & $\mathrm{D}(\mathrm{mm})$ & $\begin{array}{l}\text { Fineness } \\
\text { modulus }\end{array}$ & $\begin{array}{l}\text { Expansion due to } \\
\text { alkali reactivity }(\%)\end{array}$ \\
\hline Pebblestone & 0.125 & 4 & 3.99 & 0.22 \\
\hline
\end{tabular}

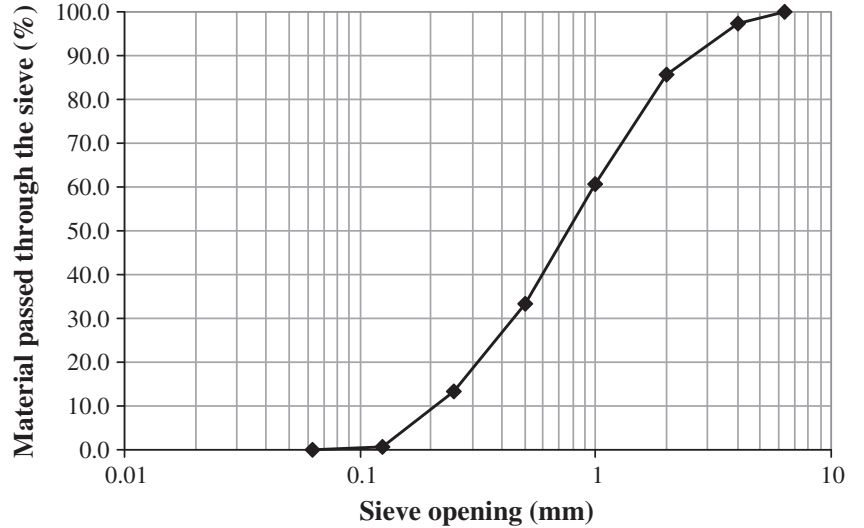

Fig. 1. Granulometric curve of the aggregate.

study. Other properties of the selected polymer additions were determined and are listed in Table 3. The solid content was determined according to the EN 480-8 method, the glass transition temperature $\left(\mathrm{T}_{\mathrm{g}}\right)$ represents the midpoint of the glass transition region observed in differential scanning calorimetry tests of polymer films, the specific mass was determined with a hydrometer and $\mathrm{pH}$ was determined with a pH meter according to ISO 4316.

\subsection{Mix design and curing method}

A P/C of $15 \%$ was chosen for the PCMs studied to assure an effective polymer-cement co-matrix $[15,31,32]$ and significant influence on the properties of cement paste, while still being potentially cost-effective in field.

While the main purpose of the studied PCMs was the assessment of their alkali reactivity potential and the intended ASTM C 1260 alkali reactivity test specifies a fixed $\mathrm{W} / \mathrm{C}$ ratio of 0.47 , the plasticizing effect of polymer additions would lead to an extremely fluid PCM if the specified W/C had been used, especially considering the high $15 \% \mathrm{P} / \mathrm{C}$ dosage. Thus, a constant flow between the PCMs and an unmodified CM was sought. While the unmodified CM's mix followed the design specified in ASTM C 1260, the W/C of PCM mixes was adjusted so that their flow fell in the $\pm 7.5 \%$ range relative to the unmodified $\mathrm{CM}$. The $\pm 7.5 \%$ acceptable range was adopted from the ASTM C 1567 alkali reactivity test for combinations of cementitious materials and aggregates. Table 4 lists the total water to cement ratio $\left(\mathrm{W}_{\text {tot }} / \mathrm{C}\right)$, comprising both the added water and the liquid content of the polymer addition used, while the water to cement ratio $(\mathrm{W} / \mathrm{C})$ comprises only the added water of the mortars studied. The flow and air content fresh properties according to the procedure described in ASTM C 1437 and C 231 (type B meter) respectively are also listed. Additional pore volume data was obtained from mercury intrusion porosimetry (MIP) tests on samples of hardened mortar. MIP tests were carried according to ASTM D4404-84 between 0.1 and $342 \mathrm{MPa}$ and the results are also presented in Table 4.

The results show that after the flow adjustment the resulting $\mathrm{W}_{\text {tot }} / \mathrm{C}$ ratio of the AS and SB PCMs is lower than that of the unmodified mortar, which indicates the usual plasticizing effect of polymer additions. The EP polymer addition, however, didn't exhibit this effect, as the resulting $\mathrm{PCM}$ required a $\mathrm{W}_{\text {tot }} / \mathrm{C}$ significantly higher than the unmodified mortar

Table 2

Chemical and mechanical properties of cement.

\begin{tabular}{|c|c|c|c|c|c|c|c|c|c|}
\hline \multicolumn{8}{|c|}{ Bogue chemical composition (\%) } & \multicolumn{2}{|c|}{$\begin{array}{l}\text { Mechanical strength at } \\
28 \text { days }(\mathrm{MPa})\end{array}$} \\
\hline $\mathrm{C}_{3} \mathrm{~S}$ & $\mathrm{C}_{2} \mathrm{~S}$ & $\mathrm{C}_{3} \mathrm{~A}$ & $\mathrm{C}_{4} \mathrm{AF}$ & $\mathrm{SO}_{3}$ & $\mathrm{Na}_{2} \mathrm{O}$ & $\mathrm{K}_{2} \mathrm{O}$ & $\mathrm{Na}_{2} \mathrm{O}_{\mathrm{eq}}$ & Compressive & Flexural \\
\hline 64.7 & 3.2 & 9.9 & 9.3 & 2.7 & 0.1 & 1.1 & 0.82 & 49.6 & 7.9 \\
\hline
\end{tabular}


to attain the same flow. While both SB PCM mixes required the same $\mathrm{W}_{\text {tot }} / \mathrm{C}$, the fresh air content was distinct, which could be related, for instance, to different quantities and type of anti-foaming agents and surfactants incorporated in the polymer additions by the respective manufacturers. While the AS addition greatly increased the air content of mortar, the EP addition significantly reduced it.

All mortar specimens were cured for a 28-day period according to the process specified in the test methods of EN 1504-3. Specimens were demoulded after $24 \mathrm{~h}$ and wrapped in film for $48 \mathrm{~h}$ to allow cement hydration, and subsequently unwrapped and cured for 25 days in standard laboratory climate to allow coalescence of polymer in PCMs.

\section{Test methods}

\subsection{Alkali reactivity tests}

To assess the influence of polymer additions on ASR, two distinct accelerated mortar bar $(25 \times 25 \times 285 \mathrm{~mm})$ tests were used, during which expansion and mass variation were monitored. Before testing, all specimens were subjected to the 28-day curing method described in Section 2.4 .

A faster test method adopted a test environment similar to that specified in ASTM C 1260. After the 28-day curing period, mortar bars were immersed in water at $80{ }^{\circ} \mathrm{C}$ during $24 \mathrm{~h}$ after which they were immersed in a $1 \mathrm{~N} \mathrm{NaOH}$ solution at $80^{\circ} \mathrm{C}$ for a period of 28 days. A slower test method was conducted under conditions similar to those specified in ASTM C 227. After the same 28-day curing period, mortar bars were vertically stored over water inside a stainless steel container kept in an oven at $38 \pm 2{ }^{\circ} \mathrm{C}$, which assured a moist ( $>90 \%$ H.R.), warm environment to accelerate ASR. To further increase ASR expansion rates, the $\mathrm{Na}_{2} \mathrm{O}_{\mathrm{eq}}$ content of mortars was increased to $1.25 \%$ of the mass of cement through the addition of the required amount of $\mathrm{NaOH}$ to the mixing water.

\subsection{SEM/EDX}

Scanning electron microscopy (SEM) observations were conducted on a JEOL JSM-6400 research grade SEM after the alkali reactivity tests to confirm expansion due to ASR. Both polished sections and fractured surface samples were coated with gold and examined. Polished sections were obtained by impregnation of mortar samples with low-viscosity epoxy resin under vacuum before polish. SEM images were obtained in both composition mode of backscattered electron imaging (COMPO) and secondary electron imaging mode (SEI). The energy dispersive X-ray (EDX) microanalysis capability was used to identify the composition of the ASR products observed.

\subsection{Differential scanning calorimetry}

Since the ASTM C 1260 alkali reactivity test imposes severe thermal conditions to the polymer-cement co-matrix and because the thermal resistance of the polymer film resulting from the polymer additions is rarely provided by the manufacturers, the thermal stability of the polymer films was assessed through differential scanning calorimetry (DSC) tests according to ISO 11357, parts 1 and 2. DSC tests also allowed determination of phase transitions and respective temperatures, such as the glass transition temperature $\left(\mathrm{T}_{\mathrm{g}}\right)$. Polymer film specimens were obtained through drying of an appropriate amount of polymer addition at room temperature for $24 \mathrm{~h}$.

\subsection{Water transport properties}

The capillary water sorption coefficient was assessed through the EN 13057 test method. This method consisted of having circular specimens of $100 \mathrm{~mm}$ diameter and $20 \mathrm{~mm}$ thickness with the trowelled test face in contact with water and measuring their weight change
Table 3

Properties of polymer additions.

\begin{tabular}{lllll}
\hline Polymer addition & $\begin{array}{l}\text { Specific mass } \\
\left(\mathrm{g} / \mathrm{cm}^{3}\right)\end{array}$ & $\begin{array}{l}\text { Solid content } \\
(\%)\end{array}$ & $\mathrm{pH}$ at $20{ }^{\circ} \mathrm{C}$ & $\mathrm{T}_{\mathrm{g}}\left({ }^{\circ} \mathrm{C}\right)$ \\
\hline SB 1 & 1.026 & 41.7 & 9.59 & 0.8 \\
SB 2 & 1.022 & 38.6 & 9.74 & 20.3 \\
AS & 1.014 & 36.2 & $9-11$ & 27.5 \\
EP & 1.075 & 54.6 & - & - \\
\hline
\end{tabular}

(water uptake) in appropriate time intervals. The sorption coefficient is the gradient of the linear portion of the weight change curve expressed as a function of the square root of time.

Additional tests were conducted to assess the water absorption of immersed hardened mortar under atmospheric pressure. Small cubic specimens of $25 \mathrm{~mm}$ side were used, to allow testing of sections of mortar bars subjected to alkali reactivity tests (ASTM C 1260). The specimens were dried in a $105{ }^{\circ} \mathrm{C}$ oven until constant weight (less than $0.1 \%$ difference in at least $24 \mathrm{~h}$ ) and then immersed in water up to $2 \mathrm{~mm}$ above the top surface and weighted again until constant weight was achieved. The resulting water absorption at ambient pressure is the volume of absorbed water expressed as percentage of the specimen's volume.

\subsection{Mechanical properties}

Compressive strength was determined according to EN 12190, while flexural strength was determined according to EN 196-1 and the modulus of elasticity in compression was determined according to method 2 of EN 13412. All mechanical properties were determined for 28 days of age.

\subsection{Stiffness damage tests}

Stiffness damage tests (SDTs) were conducted on $25 \times 25 \times 100 \mathrm{~mm}$ specimens, as this allowed testing of two sections of each mortar bar used in alkali reactivity tests. The test method followed the one described by Smaoui et al. [33] and consisted of 5 cycles of compressive loading up to $10 \mathrm{MPa}$ and unloading at a fixed $0.1 \mathrm{MPa} / \mathrm{s}$. A minimum of two specimens were tested for each combination of a given mortar type and state (undamaged or subjected to an alkali reactivity test). The energy dissipated during the first cycle (area of the hysteresis comprehended between the loading and unloading curves) and the accumulated plastic strain after 5 cycles were used to quantify microcracking intensity.

\section{Results and discussion}

The results of mechanical tests (Fig. 2) show that generally the polymer additions significantly reduced the compressive strength but didn't significantly affect the flexural strength of mortar (Fig. 2a). However, the polymer addition used in the SB 2 PCM was able to significantly improve the flexural strength over the unmodified Ref $\mathrm{CM}$ without compressive strength loss.

Table 4

Mix design, flow and pore volume data.

\begin{tabular}{|c|c|c|c|c|c|c|c|}
\hline \multirow{2}{*}{$\begin{array}{l}\text { Mortar } \\
\text { mixes }\end{array}$} & \multicolumn{4}{|c|}{ Mix design } & \multicolumn{2}{|c|}{ Fresh properties } & \multirow{2}{*}{$\begin{array}{l}\begin{array}{l}\text { Hardened } \\
\text { properties }\end{array} \\
\text { MIP pore } \\
\text { volume (\%) }\end{array}$} \\
\hline & $\mathrm{P} / \mathrm{C}(\%)$ & $\mathrm{A}: \mathrm{C}$ & $\mathrm{W} / \mathrm{C}$ & $\mathrm{W}_{\text {tot }} / \mathrm{C}$ & Flow (\%) & Air content (\%) & \\
\hline Ref CM & 0 & $1: 3$ & 0.47 & 0.47 & 124 & 7.6 & 11.5 \\
\hline SB 1 PCM & 15 & $1: 3$ & 0.11 & 0.32 & 125 & 10.1 & 12.6 \\
\hline SB 2 PCM & 15 & $1: 3$ & 0.08 & 0.32 & 129 & 6.5 & 7.7 \\
\hline AS PCM & 15 & $1: 3$ & 0.16 & 0.42 & 130 & 14.8 & 8.6 \\
\hline EP PCM & 15 & $1: 3$ & 0.45 & 0.57 & 122 & 2.6 & 14.3 \\
\hline
\end{tabular}



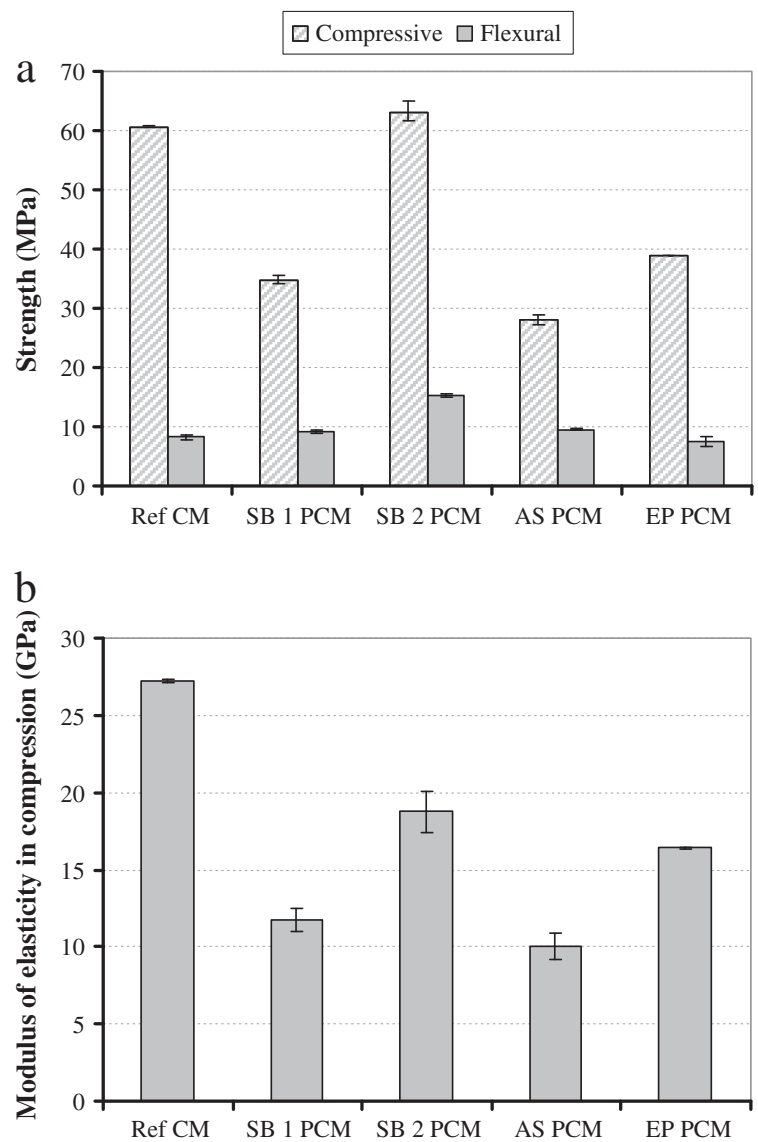

Fig. 2. Mechanical properties of the mortars studied: a) compressive and flexural strength; b) modulus of elasticity in compression.

The significant performance improvement of the SB 2 PCM over the SB 1 PCM, both modified with an SB polymer addition and with similar W/C ratio, may be justified by a possible higher amount of anti-foaming agent in the SB 2 addition. The significantly lower fresh air content of SB 2 PCM (Table 4) suggests that the SB 2 polymer addition may have in fact a higher amount of anti-foaming agent when compared to the SB 1 polymer addition. Additionally, SB 2 PCM also showed the lowest pore volume according to MIP tests (Table 4), which includes pores in the capillary range. Despite having

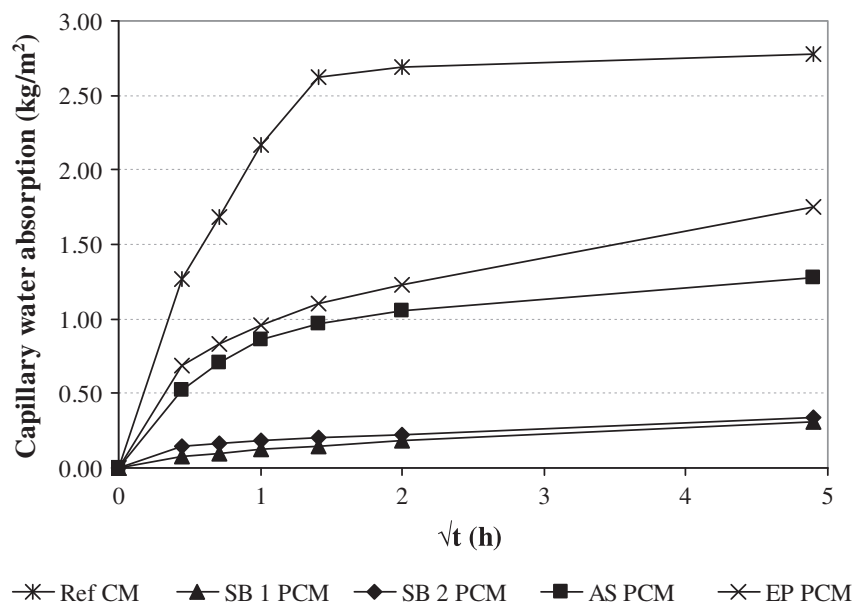

Fig. 3. Capillary water absorption.
Table 5

Water absorption of the mortars studied.

\begin{tabular}{llll}
\hline Mortars & $\begin{array}{l}\text { Capillary sorption } \\
\text { coefficient } \\
\left(\mathrm{kg} /\left(\mathrm{m}^{2} \mathrm{~h}^{0.5}\right)\right)\end{array}$ & $\begin{array}{l}\text { Water absorption } \\
\text { under atmospheric } \\
\text { pressure }(\%)\end{array}$ & $\begin{array}{l}\text { Water vapor } \\
\text { permeability } \\
(\mathrm{kg} /(\mathrm{Pa} \cdot \mathrm{m} \cdot \mathrm{s}))\end{array}$ \\
\hline Ref CM & 1.65 & 11.5 & $8.80 \times 10^{-12}$ \\
SB 1 PCM & 0.04 & 5.8 & $3.44 \times 10^{-12}$ \\
SB 2 PCM & 0.04 & 4.3 & $1.11 \times 10^{-12}$ \\
AS PCM & 0.07 & 8.9 & $8.99 \times 10^{-12}$ \\
EP PCM & 0.18 & 11.3 & $5.97 \times 10^{-12}$ \\
\hline
\end{tabular}

the lowest air content, the EP PCM showed the highest MIP pore volume (Table 4), which may justify its low compressive strength.

As expected from previous experience [29], and according to Fig. 2b), polymer additions reduced the modulus of elasticity in compression of CM. However, EP and SB 2 PCMs had considerably higher modulus than the rest of the PCMs.

Given the fact that water plays an important role in ASR development and that the ASTM C 1260 alkali reactivity test requires the mortar bar specimens to be in permanent immersion in a $\mathrm{NaOH}$ solution, particular attention was given to water transport properties of PCMs.

Fig. 3 shows the weight change of the mortars studied due to capillary water absorption. The stabilization of the weight change of the unmodified Ref CM shortly after the $1 \mathrm{~h}$ mark was due to the absorbed water front reaching the top of the specimen. The sorption coefficient of the water absorption curves shown in Fig. 3 and the water absorption under atmospheric pressure of the mortars studied are reported in Table 5. As expected, considering the previous experience with AS and SB PCMs [29], the reduced water absorption of PCMs was confirmed. However, the water absorption of the EP PCM was similar to that of the Ref CM.

Even though polymers usually increase the total pore volume of mortar due to their air-entraining effect, the increase is reflected mainly in the larger pore dimensions and thus contributes to reduce the capillary absorption by interrupting the network of capillary pores. Polymer particles can also fill the smaller capillary pores of the cement paste, explaining the usually reported reduced pore volume of PCMs in the capillary range of pore radius and a shift to the lower pore dimensions in this range [25,34-36], although this effect may depend on the polymer type.

The results of the alkali reactivity test in $\mathrm{NaOH}$ solution bath at $80{ }^{\circ} \mathrm{C}$ show that in that specific ASR inducing environment all PCMs expanded more than the unmodified Ref CM, as shown in Fig. 4.

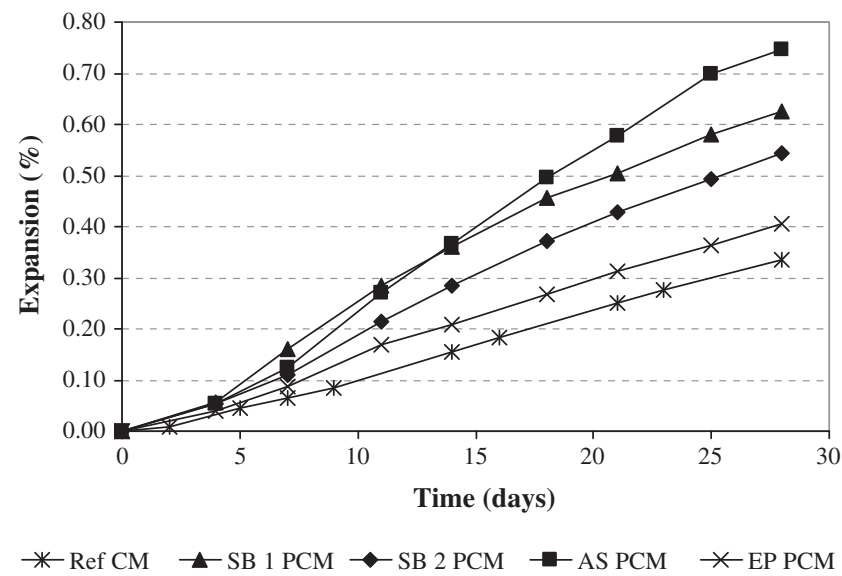

Fig. 4. Expansion due to ASR in $1 \mathrm{~N} \mathrm{NaOH}$ solution bath test. 


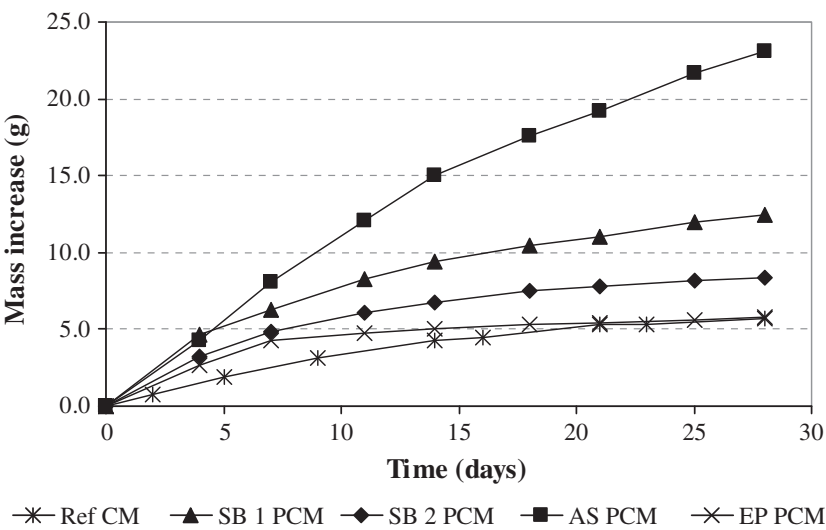

Fig. 5. Weight change during the $1 \mathrm{~N} \mathrm{NaOH}$ solution bath test.

The weight change of specimens was also monitored after the specimens were immersed in the $\mathrm{NaOH}$ solution and the results showed that the weight change of PCMs in the $\mathrm{NaOH}$ solution was higher (Fig. 5). This suggests that, unexpectedly, the $\mathrm{NaOH}$ solution uptake of PCMs in the alkali reactivity test conditions was higher despite their water absorption determined at $21^{\circ} \mathrm{C}$ being lower than that of the unmodified Ref CM, as shown in Table 5 .

With higher $\mathrm{NaOH}$ solution uptake during the alkali reactivity test, the SB and AS PCMs were expected to have been more extensively affected by ASR, as it increased the exposure of their aggregate particles to the attack of the $\mathrm{OH}^{-}$ions present in the $\mathrm{NaOH}$ solution and also increasing the availability of water and $\mathrm{Na}^{+}$ions necessary for the formation and expansion of ASR gel. Thus, a higher amount of ASR gel was also expected in these PCMs.

The comparison of water absorption under atmospheric pressure before and after the alkali reactivity tests expressed in Fig. 8 seems to confirm that a higher amount of ASR gel was produced in PCMs compared to the Ref $\mathrm{CM}$. As the specimens were dried at $105^{\circ} \mathrm{C}$ prior to the determination of water absorption, the ASR gel was expected to be dehydrated in this process, exposing the voids resulting from the silica dissolution in the aggregate particles affected by ASR and increasing the water absorption.

Although the mechanism responsible for the higher uptake of $\mathrm{NaOH}$ solution of PCMs was not clarified, it could not have been the main reason behind their higher expansion compared to the unmodified Ref CM. In the less aggressive test environment of moist, $38^{\circ} \mathrm{C}$, PCMs still expanded more than the unmodified Ref CM (Fig. 6), despite equal alkali content (raised to $1.25 \% \mathrm{NaO}_{\mathrm{eq}}$ during mixing) and lower mass increase due to water absorption, shown in Fig. 7. Additionally, in the moist (>90\% H.R.), $38{ }^{\circ} \mathrm{C}$ environment, the mass increase due to water absorption more closely agrees with the relevant water transport property

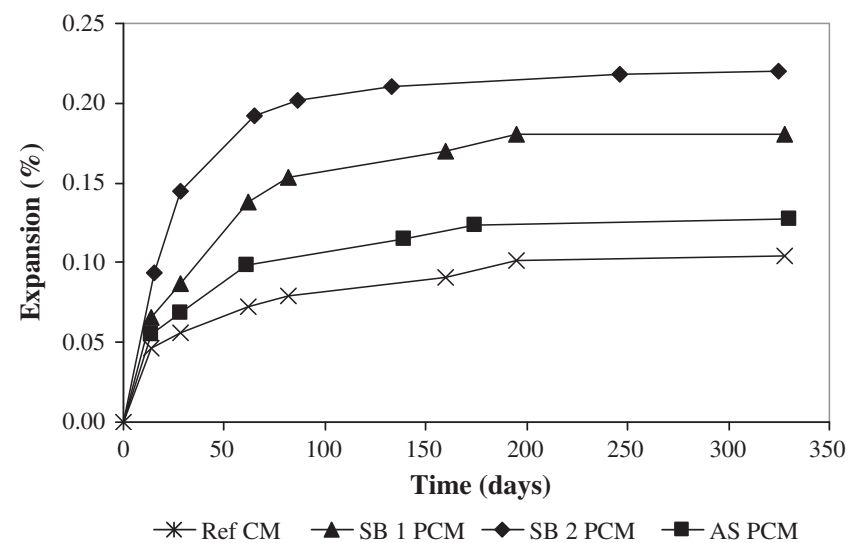

Fig. 6. Expansion due to ASR in moist $38{ }^{\circ} \mathrm{C}$ test.

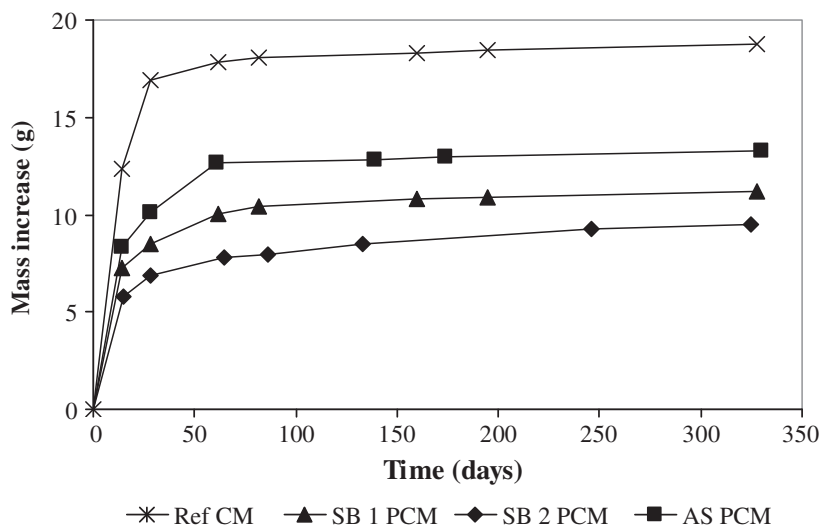

Fig. 7. Weight change during the moist $38{ }^{\circ} \mathrm{C}$ test.

determined at $21{ }^{\circ} \mathrm{C}$, which should be water vapor permeability (Table 5), with PCMs showing both lower mass increase and lower water vapor permeability than the unmodified Ref CM. Other mechanisms thus must have influenced expansion.

Mortars with higher porosity can accommodate a higher volume of ASR gel, thus relieving the expansive pressure caused by its water absorption. On the other hand the internal stresses developed due to ASR are expected to result in higher expansion in mortars with lower modulus of elasticity. PCMs might also have higher coefficient of linear thermal expansion [35,36], but its influence on the expansion results was not critical, as the faster alkali reactivity test in $80^{\circ} \mathrm{C} \mathrm{NaOH}$ solution was preceded by a $24 \mathrm{~h}$ period of $80{ }^{\circ} \mathrm{C}$ plain water immersion and still AS and SB PCMs expanded significantly more than the unmodified Ref $\mathrm{CM}$. The $\mathrm{OH}^{-}$ions present in the concrete and mortar pore solution have been reported to improve the hardening process of epoxy, leading to the research of the possibility of using hardener-free epoxy in mortar and concrete [37-39] and self-healing epoxy-modified cement mortar [40]. Saccani and Motori [30] reported that curing of an epoxy film similar to that used in the present study in an $80{ }^{\circ} \mathrm{C}$ highly alkaline saturated $\mathrm{Ca}(\mathrm{OH})_{2}$ solution improved its tensile strength and decreased its elongation at break, probably due to the increased crosslinking degree promoted by $\mathrm{OH}^{-}$ions. A similar mechanism might have influenced the expansion of the EP PCM in the $80{ }^{\circ} \mathrm{C} \mathrm{NaOH}$ solution bath of the alkali reactivity test.

Even though PCMs expanded more than the Ref CM, expansion shouldn't be the only measure of performance of mortar or concrete affected by ASR whenever materials with distinct mechanical properties are compared. Ultimately, resistance of concrete or mortar to cracking and degradation under ASR action should be used to assess their performance.

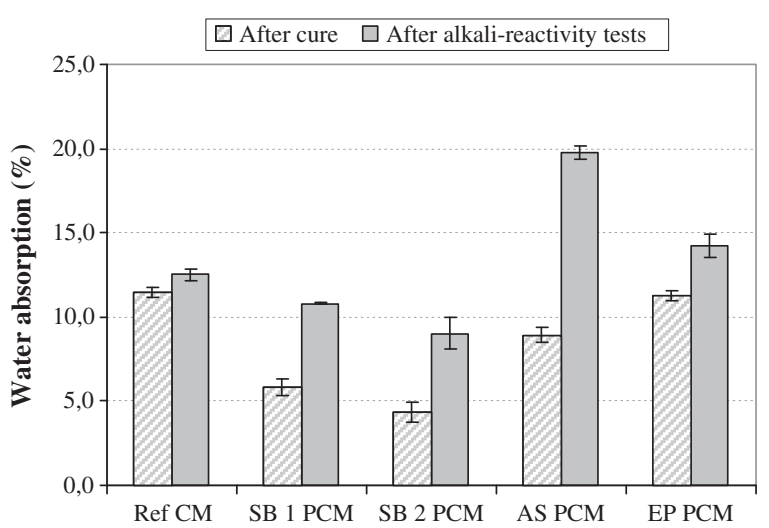

Fig. 8. Comparison of water absorption before and after the alkali reactivity test. 

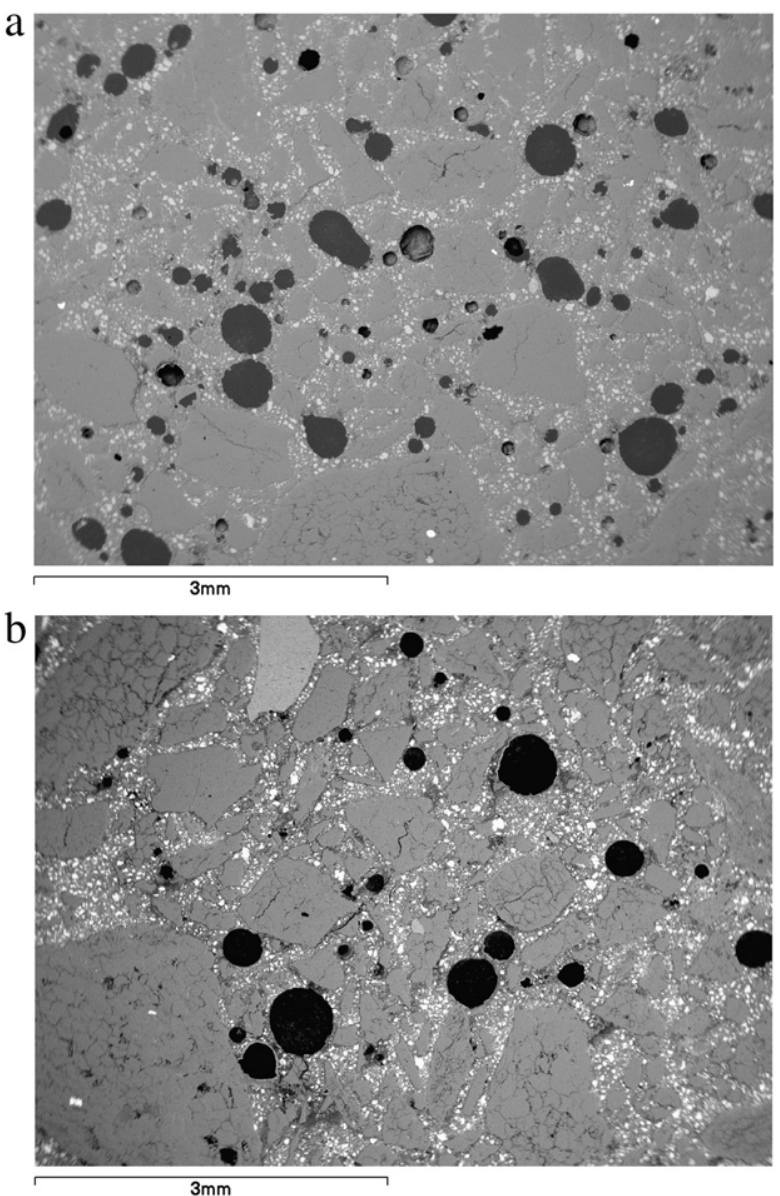

Fig. 9. Overall porosity of PCMs shown in SEM images in COMPO mode: a) SB 1 PCM; b) SB 2 PCM.

SEM/EDX observations followed the alkali reactivity tests to confirm the presence of ASR products and look for physical evidences of degradation or alternative causes for the observed higher expansion in PCMs compared to the unmodified Ref CM.

SEM images in Fig. 9 confirmed the higher amount of macropores due to entrained air of SB 1 PCM (Fig. 9a) compared to the SB 2 PCM (Fig. 9b). The darker areas of Fig. 9 correspond to pores impregnated with epoxy resin during preparation of the polished samples.

ASR gel was detected in all specimens subjected to the alkali reactivity test and pores were usually found filled or lined with ASR gel, as shown in Fig. 10a). In this figure, the darker area inside the circular pore corresponds to epoxy resin impregnated during preparation of the polished samples while the rest of the pore area is filled with ASR gel with distinct textures, for which EDX analysis is given in Fig. 10b). The EDX analysis showed that the $\mathrm{Ca} / \mathrm{Si}$ ratio of the gel near the pore rim was higher than that of the inner textured gel. The textured gel observed inside the pores of polished samples corresponded to crystalline ASR products, as shown in the fractured sample image of Fig. 11, while the gel found near the pore rim was the more common amorphous ASR gel.

Evidence of polymer film formation in the cement paste of PCMs is not usually easy to observe without previous acid dissolution of the cement hydration products, especially in ASR-affected specimens where most existing voids are filled with ASR gel. However, evidence of polymer film bridging aggregate and cement paste was observed on a fractured sample of AS PCM, as shown in Fig. 11b).

Additional evidence of ASR products was found near the reaction sites, both at the boundary of dense aggregate particles and at the interior surfaces exposed in porous aggregate particles. Fig. 12a) shows the coexistence of porous and homogeneous aggregate particles. a

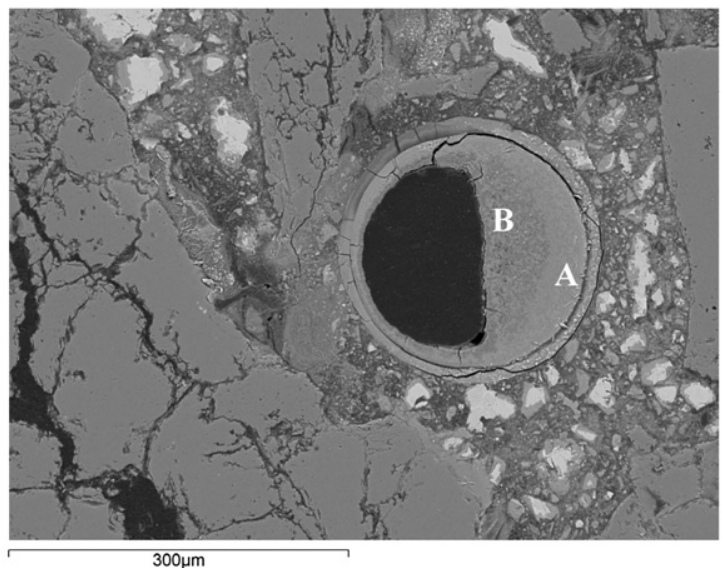

b

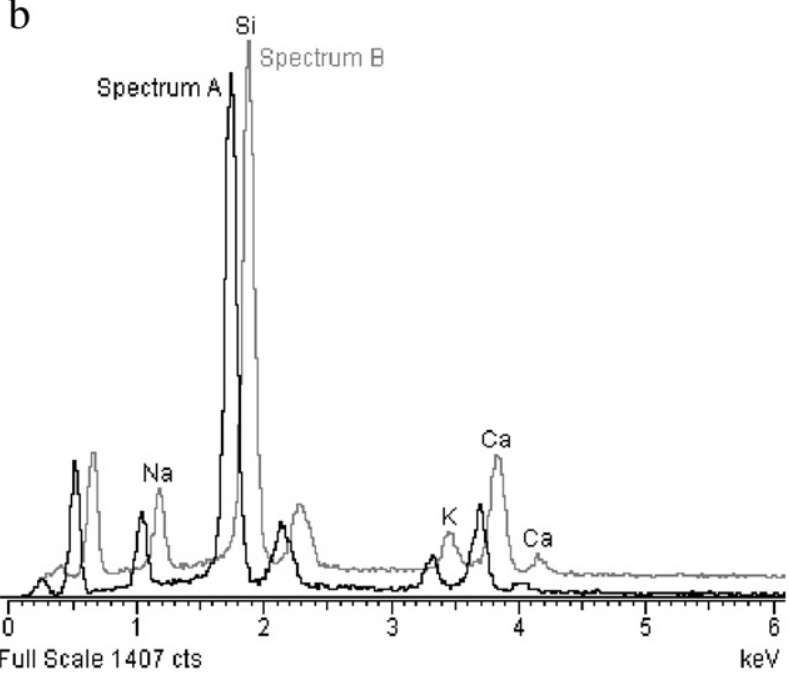

Fig. 10. ASR gel in a pore of a SB 2 PCM sample (SEM image of polished sample in COMPO mode): a) pore partially filled with gel; b) EDX spectrum of ASR gel observed in Fig. 9a), normalized to the Si peak.

Fig. 12b) shows in more detail the porous sites observed in aggregate particles similar to that found in Fig. 12a) and the presence of ASR gel with an EDX spectrum similar to that of Fig. 10b) is pointed out.

SEM observations were able to detect widespread microcracking in the cement paste of the unmodified Ref CM (Fig. 13), a feature not present in PCMs, where significant damage was only present in the interior of the aggregate particles. Fig. 14 shows that despite extensive evidence of ASR gel and degradation of the aggregate particles and significantly higher expansion (Fig. 4), microcracking in the cement paste was much less frequent in the SB 1 PCM compared to the Ref CM. Similar conclusions were drawn from the observations of the remaining PCMs studied. SEM observations thus suggested a potential for polymers to delay the onset of cracking and degradation of mortar or concrete caused by ASR.

As DSC tests of the polymer films (Fig. 15) showed no relevant state changes at temperatures higher than $\mathrm{T}_{\mathrm{g}}$ (Table 3 ) and up to $200{ }^{\circ} \mathrm{C}$, it is expected that the integrity of the polymer-cement co-matrix and the potential for higher resistance to microcracking of PCMs remained even in the $80{ }^{\circ} \mathrm{C} \mathrm{NaOH}$ solution bath test.

Stiffness damage tests (SDTs) were used to quantitatively assess the microcracking intensity in mortar bar specimens and the results are listed in Table 6. As the expansion level observed in the slower alkali reactivity tests in $38{ }^{\circ} \mathrm{C}$ moist environment was not sufficiently high to give rise to significant microcracking, only the results of SDTs on undamaged specimens (after 28 day cure) and specimens subjected to the $80{ }^{\circ} \mathrm{C} \mathrm{NaOH}$ solution bath test are presented. In the 

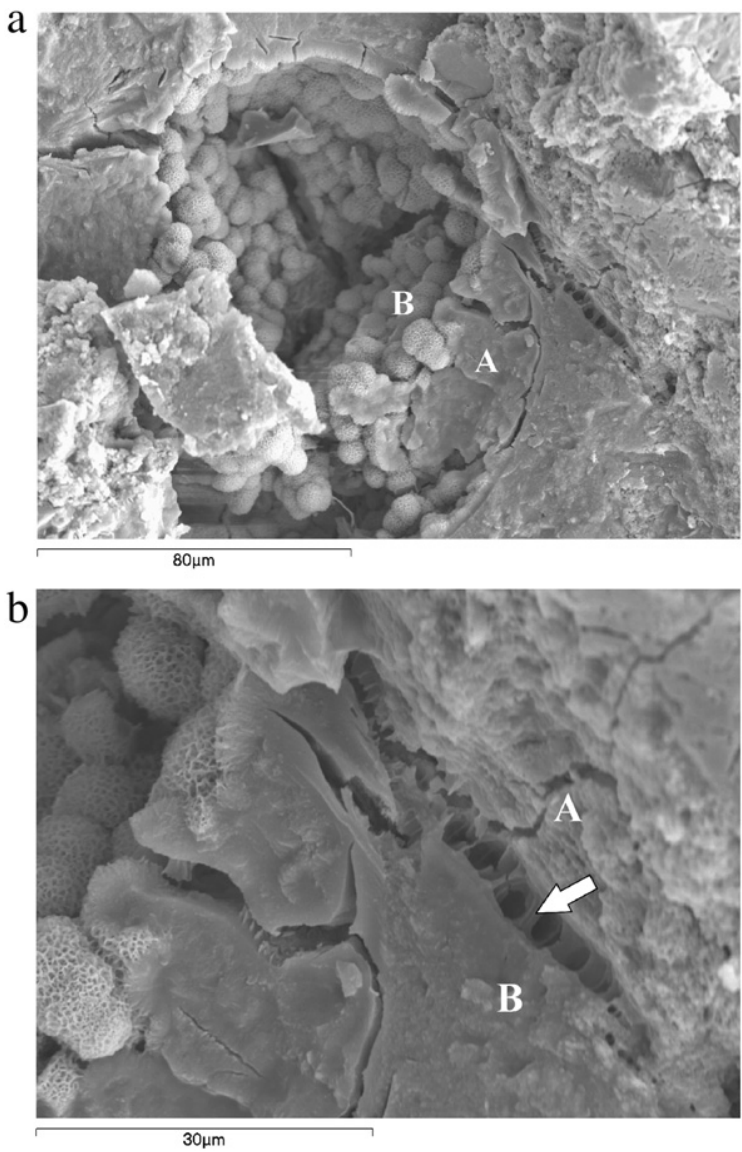

Fig. 11. Crystalline ASR gel in pore and evidence of polymer "bridges" (SEM image of fractured AS PCM sample in SEI mode): a) pore containing amorphous (A) and crystalline (B) ASR gel; b) detail of Fig. 10a) showing evidence of polymer film bridging aggregate $(A)$ and cement paste $(B)$.

presence of existing microcracks, the energy dissipated in the 1st cycle and the plastic deformation after 5 cycles in SDTs are expected to increase. The variation of both SDT parameters after the alkali reactivity test is also presented in Table 6 relative to the results of undamaged specimens.

For SB 1 PCM there was a lower variation of both parameters compared to that observed for the unmodified Ref CM. For SB 2 and AS PCMs no significant microcracking existed after the alkali reactivity test, as there was only a slight increase or even a reduction (thus a negative variation) of both parameters, which may be due to their high $(>10 \%)$ coefficients of variation (CVs). However, despite low CVs, the EP PCM exhibited significant reduction of both the energy dissipated in the 1 st cycle and the plastic deformation after 5 cycles. The resistance to microcracking and the improved mechanical performance of the EP PCM may be due to both the increased hardening of epoxy in $\mathrm{OH}^{-}$rich environments [30] and the self-healing ability of epoxy-modified cement-based materials [40].

\section{Conclusions}

All the PCMs studied exhibited lower capillary sorption coefficient and water absorption under atmospheric pressure than the unmodified Ref CM, thus showing potential for a reducing effect in ASR due to lower exposure of ASR gel to water necessary for its expansion. Additionally, other known properties of PCMs relevant to ASR, such as lower ionic mobility, improved ITZ and lower availability of $\mathrm{Ca}(\mathrm{OH})_{2}$, were believed to potentially reduce ASR-related expansion.

Despite this, the expansion results of PCMs were higher than those of the Ref CM. This was verified in both alkali reactivity test environments
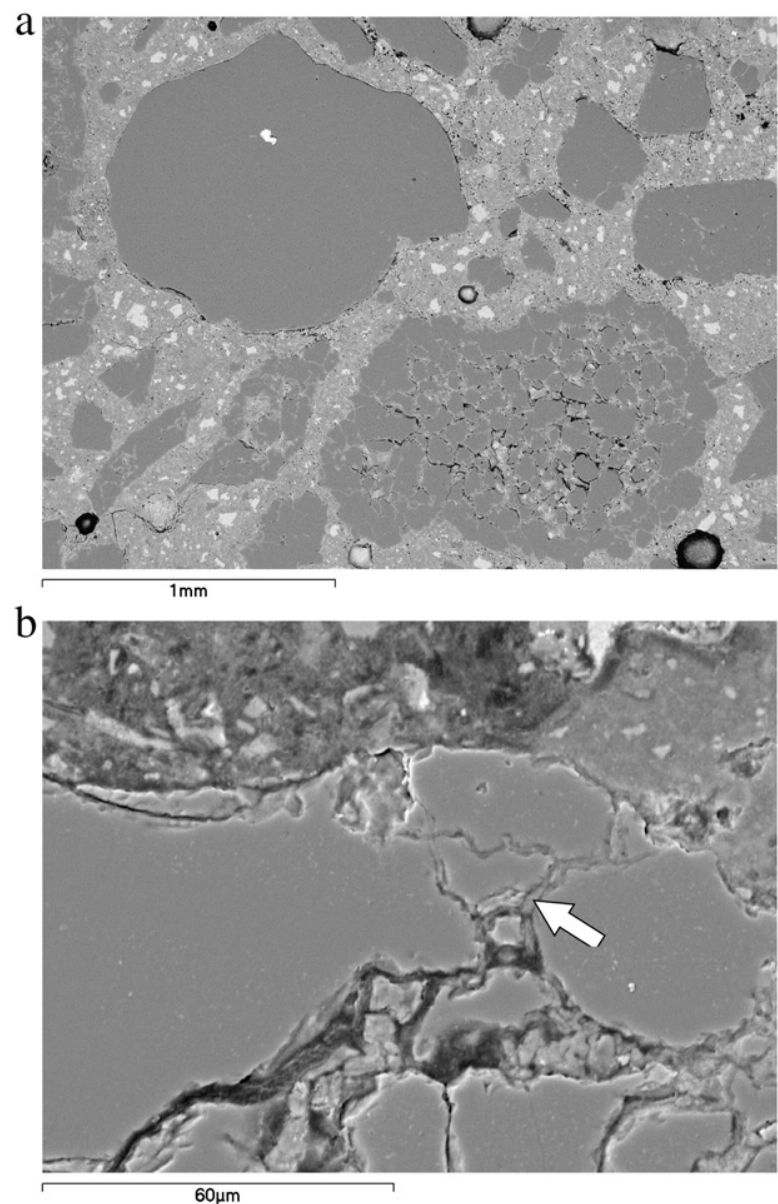

Fig. 12. Aggregate particles affected by ASR: a) porous aggregate particle (bottom) and dense particle (top) (SEM image of Ref CM sample in COMPO mode); b) porous site of aggregate particle; arrow points out the presence of ASR gel (SEM image of AS PCM sample in COMPO mode).

composing of an $80^{\circ} \mathrm{C} \mathrm{NaOH}$ solution bath and storage of mortar bar specimens with increased alkali content in a moist, $38{ }^{\circ} \mathrm{C}$ environment.

Although PCMs expanded more under the action of ASR, subsequent SEM observations of sections of specimens subjected to the $80^{\circ} \mathrm{C} \mathrm{NaOH}$ solution bath revealed significantly reduced microcracking in their cement paste compared to that of the unmodified CM, even in AS PCM samples which expanded more than twice as much. This behavior was in agreement with the often reported higher tensile strength, ductility

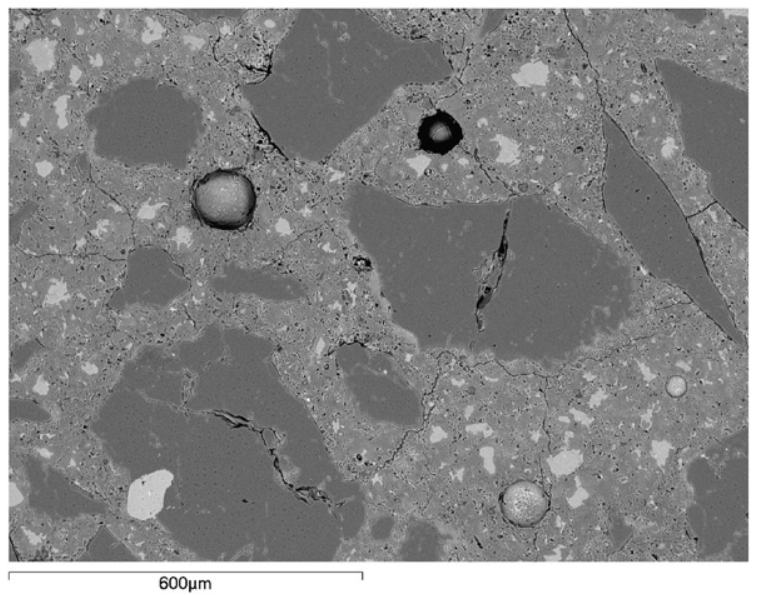

Fig. 13. Widespread microcracking in the cement paste of Ref CM (SEM image in COMPO mode). 


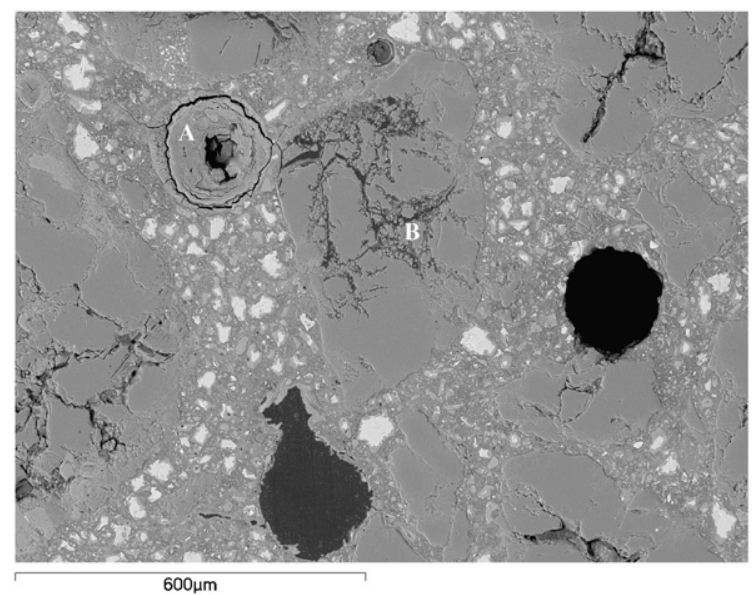

Fig. 14. Absence of microcracking in the cement paste of the SB 1 PCM despite extensive evidence of ASR gel in the pores (A) and aggregate particle degradation (B) (SEM image in COMPO mode).

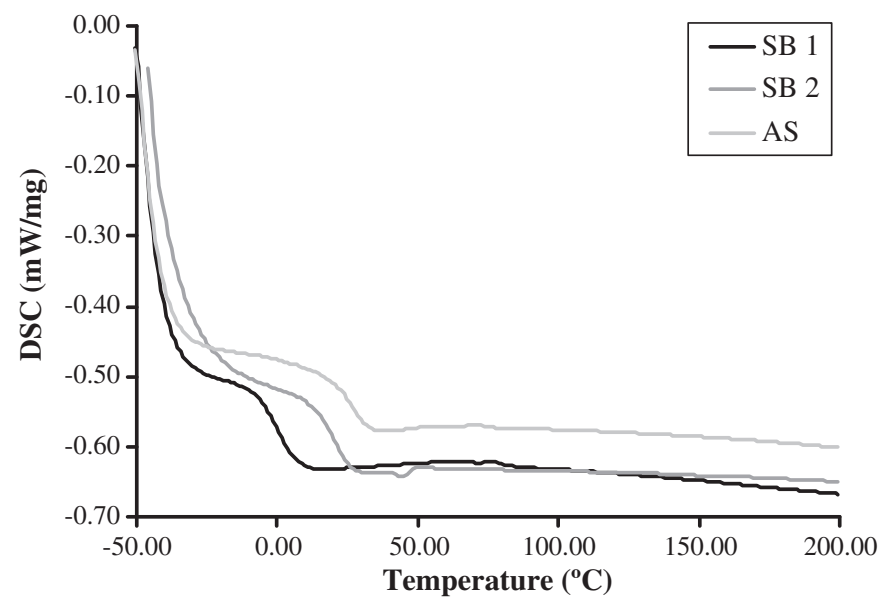

Fig. 15. DSC tests of SB 1, SB 2 and AS polymer films.

and resistance to microcracking of PCMs, which, according to DSC tests of polymer films, likely remained in the aggressive $80{ }^{\circ} \mathrm{C}$ environment of the alkali reactivity tests.

SDTs allowed quantification of the microcracking intensity in mortar bars and further confirmed the suggested higher resistance of PCMs to ASR-related damage. This was shown in the variation of both plastic deformation and energy dissipated in the first cycle of loading and unloading of mortar bar specimens subjected to the faster $80{ }^{\circ} \mathrm{C} \mathrm{NaOH}$ solution bath test, compared to sound mortar bar specimens. For PCMs, variation of these parameters was consistently and significantly lower than that of the unmodified Ref CM, showing the potential for polymers to reduce ASR-related damage in mortar and concrete.

Additionally, higher expansion of PCMs was thus considered to be a consequence of their lower modulus of elasticity, while differences in porosity were also identified as possible factors influencing expansion.

\section{Acknowledgments}

The authors acknowledge the financial support from FCT Fundação para a Ciência e a Tecnologia (Portugal) given to the research project PTDC/ECM/101810/2008 - Polymer-modified Cement Mortars for the Repair of Concrete Structures, whose scope included the present study.
Table 6

Results of stiffness damage tests.

\begin{tabular}{|c|c|c|c|}
\hline & Undamaged & $\begin{array}{l}\text { After } 28 \text { days in } \\
80^{\circ} \mathrm{C} \mathrm{NaOH} \text { solution }\end{array}$ & Variation (\%) \\
\hline \multicolumn{4}{|l|}{ Ref CM (unmodified) } \\
\hline $\begin{array}{l}\text { Plastic deformation } \\
\text { after } 5 \text { cycles }(\mu \mathrm{m} / \mathrm{m})\end{array}$ & 48.1 & 101.5 & 111.0 \\
\hline CV (\%) & 11.1 & 10 & \\
\hline $\begin{array}{l}\text { Energy dissipated } \\
\text { in the } 1 \text { st cycle }\end{array}$ & 202.3 & 621.6 & 207.3 \\
\hline CV (\%) & 14.8 & 19.4 & \\
\hline \multicolumn{4}{|l|}{$S B 1 P C M$} \\
\hline $\begin{array}{l}\text { Plastic deformation } \\
\text { after } 5 \text { cycles }(\mu \mathrm{m} / \mathrm{m})\end{array}$ & 77.2 & 128.8 & 66.8 \\
\hline CV (\%) & 11.2 & 7.3 & \\
\hline $\begin{array}{l}\text { Energy dissipated } \\
\text { in the } 1 \text { st cycle }\end{array}$ & 390.8 & 778.7 & 99.3 \\
\hline CV (\%) & 2.7 & 11.8 & \\
\hline \multicolumn{4}{|l|}{ SB 2 PCM } \\
\hline $\begin{array}{l}\text { Plastic deformation } \\
\text { after } 5 \text { cycles }(\mu \mathrm{m} / \mathrm{m})\end{array}$ & 127.3 & 111.7 & -12.3 \\
\hline CV (\%) & 10.8 & 5.5 & \\
\hline $\begin{array}{l}\text { Energy dissipated } \\
\text { in the } 1 \text { st cycle }\end{array}$ & 664.7 & 676.8 & 1.8 \\
\hline CV (\%) & 7.9 & 11.1 & \\
\hline \multicolumn{4}{|l|}{ AS PCM } \\
\hline $\begin{array}{l}\text { Plastic deformation } \\
\text { after } 5 \text { cycles }(\mu \mathrm{m} / \mathrm{m})\end{array}$ & 254.1 & 168.6 & -33.6 \\
\hline $\mathrm{CV}(\%)$ & 24.9 & 2.1 & \\
\hline $\begin{array}{l}\text { Energy dissipated } \\
\text { in the } 1 \text { st cycle }\end{array}$ & 1218.2 & 1101.5 & -9.6 \\
\hline CV (\%) & 4.2 & 5.5 & \\
\hline \multicolumn{4}{|l|}{ EP PCM } \\
\hline $\begin{array}{l}\text { Plastic deformation } \\
\text { after } 5 \text { cycles }(\mu \mathrm{m} / \mathrm{m})\end{array}$ & 235.6 & 135.6 & -42.4 \\
\hline CV (\%) & 3.4 & 6.7 & \\
\hline $\begin{array}{l}\text { Energy dissipated } \\
\text { in the } 1 \text { st cycle }\end{array}$ & 1688.9 & 765.4 & -54.7 \\
\hline CV (\%) & 0.7 & 8.3 & \\
\hline
\end{tabular}

\section{References}

[1] ISE - The Institution of Structural Engineers, Structural Effects of Alkali-Silica Reaction, Technical Guidance on the Appraisal of Existing Structures, SETO Ltd., London, 1992. (Addendum April 2010).

[2] S. Chatterji, Chemistry of alkali-silica reaction and testing of aggregates, Cem. Concr. Compos. 27 (2005) 788-795.

[3] B. Fournier, M.-A. Bérubé, Alkali-aggregate reaction in concrete: a review of basic concepts and engineering implications, Can. J. Civ. Eng. 27 (2000) 167-191.

[4] J. Duchesne, M.-A. Bérubé, Long-term effectiveness of supplementary cementing materials against alkali-silica reaction, Cem. Concr. Res. 31 (2001) 1057-1063.

[5] J. Duchesne, M.-A. Bérubé, The effectiveness of supplementary cementing materials in suppressing expansion due to ASR: another look at the reaction mechanisms - part 1: concrete expansion and portlandite depletion, Cem. Concr. Res. 24 (1994) 73-82.

[6] R.F. Bleszynski, M.D.A. Thomas, Microstructural studies of alkali-silica reaction in fly ash concrete immersed in alkaline solutions, Adv. Cem. Based Mater. 7 (1998) 66-78.

[7] X. Hou, L.J. Struble, R.J. Kirkpatrick, Formation of ASR gel and the roles of C-S-H and portlandite, Cem. Concr. Res. 34 (2004) 1683-1696.

[8] T. Ichikawa, M. Miura, Modified model of alkali-silica reaction, Cem. Concr. Res. 37 (2007) 1291-1297.

[9] V.S. Ramachandran, Alkali-aggregate expansion inhibiting admixtures, Cem. Concr. Compos. 20 (1998) 149-161.

[10] Y. Ohama, D. Katsunori, M. Kakegawa, Inhibiting alkali-aggregate reaction with chemical admixtures, in: K. Okada, S. Nishibayashi, M. Kawamura (Eds.), Proceedings of the 8th International Conference on Alkali-Aggregate Reaction (ICAAR), The Society of Materials Science, Kyoto, Japan, 1989, pp. 253-258.

[11] X. Feng, M.D.A. Thomas, T.W. Bremner, B.J. Balcom, K.J. Folliard, Studies on lithium salts to mitigate ASR-induced expansion in new concrete - a critical review, Cem. Concr. Res. 35 (2005) 1789-1796.

[12] M.M. El-Hawary, A. Abdul-Jaleel, Durability assessment of epoxy modified concrete, Constr. Build. Mater. 24 (2010) 1523-1528.

[13] G. Li, X. Zhao, C. Rong, Z. Wang, Properties of polymer modified steel fiberreinforced cement concretes, Constr. Build. Mater. 24 (2010) 1201-1206. 
[14] F.A. Shaker, A.S. El-Dieb, M.M. Reda, Durability of styrene-butadiene latex modified concrete, Cem. Concr. Res. 27 (1997) 711-720.

[15] Z. Yang, X. Shi, A.T. Creighton, M.M. Peterson, Effect of styrene-butadiene rubber latex on the chloride permeability and microstructure of Portland cement mortar, Constr. Build. Mater. 23 (2009) 2283-2290.

[16] S. Pascal, A. Alliche, Ph. Pilvin, Mechanical behaviour of polymer modified mortars, Mater. Sci. Eng., A 380 (2004) 1-8.

[17] P. Soroushian, A. Tlili, Effects of latex modification on the failure mechanism and engineering properties of concrete, in: L.A. Kuhmann, D.G. Walters (Eds.) Polymer-Modified Hydraulic-Cement Mixtures, STP 1176, ASTM, Philadelphia, 1993, pp. 104-119.

[18] M.S.S. Ribeiro, A.F. Gonçalves, F.A.B. Branco, Styrene-butadiene polymer action on compressive and tensile strengths of cement mortars, Mater. Struct. 41 (2008) 1263-1273.

[19] J.A. Rossignolo, Interfacial interactions in concretes with silica fume and SBR latex, Constr. Build. Mater. 23 (2009) 817-821.

[20] H. Schorn, M. Schiekel, Polymers as microcrack stopper in concrete observed in ESEM, in: M. Maultzsch (Ed.), Proceedings of the 11th International Congress on Polymers in Concrete, BAM Federal Institute for Materials Research and Testing, Berlin, 2004, pp. 11-18.

[21] J.A. Larbi, J.M. Bijen, Interaction of polymers with Portland cement during hydration: a study of the chemistry of the pore solution of polymer-modified cement systems, Cem. Concr. Res. 20 (1990) 139-147.

[22] M. Gretz, J. Plank, An ESEM investigation of latex film formation in cement pore solution, Cem. Concr. Res. 41 (2011) 184-190.

[23] S. Chandra, P. Flodin, Interactions of polymers and organic admixtures on Portland cement hydration, Cem. Concr. Res. 17 (1987) 875-890.

[24] R. Wang, P. Wang, Hydration of cement in the presence of SBR dispersion and powder, in: J.B. Aguiar, S. Jalali, A. Camões, R.M. Ferreira (Eds.), Proceedings of the 13th International Congress on Polymers in Concrete, Funchal, 2010, pp. 109-115.

[25] I. Ray, A.P. Guptab, M. Biswas, Physicochemical studies on single and combined effects of latex and superplasticiser on Portland cement mortar, Cem. Concr. Compos. 18 (1996) 343-355.

[26] E. Knapen, D. Van Gemert, Cement hydration and microstructure formation in the presence of water-soluble polymers, Cem. Concr. Res. 39 (2009) 6-13.

[27] M.U.K. Afridi, Y. Ohama, M.Z. Iqbal, K. Demura, Behaviour of $\mathrm{Ca}(\mathrm{OH})_{2}$ in polymer modified mortars, Int. J. Cem. Compos. Lightweight Concrete 11 (1989) 235-244.
[28] M.U.K. Afridi, Y. Ohama, M.Z. Iqbal, K. Demura, Morphology of $\mathrm{Ca}(\mathrm{OH})_{2}$ in polymer-modified mortars and effect of freezing and thawing action on its stability, Cem. Concr. Compos. 12 (1990) 163-173.

[29] M.S.S. Ribeiro, Cement mortars modified with polymeric admixtures, $\mathrm{PhD}$ Thesis, Technical University of Lisbon, Instituto Superior Técnico (in Portuguese), 2004.

[30] A. Saccani, A. Motori, The effect of polymer addition on alkali silica reactions in cementitious mortars, Mater. Struct. 34 (2001) 373-377.

[31] M.U.K. Afridi, Y. Ohama, K. Demura, M.Z. Iqbal, Development of polymer films by the coalescence of polymer particles in powdered and aqueous polymer-modified mortars, Cem. Concr. Res. 33 (2003) 1715-1721.

[32] A. Beeldens, D. Van Gemert, H. Schorn, Y. Ohama, L. Czamecki, From microstructure to macrostructure: an integrated model of structure formation in polymer-modified concrete, Mater. Struct. 38 (2005) 601-607.

[33] N. Smaoui, M.-A. Bérubé, B. Fournier, B. Bissonnette, B. Durand, Evaluation of the expansion attained to date by concrete affected by alkali-silica reaction - part I: experimental study, Can. J. Civ. Eng. 31 (2004) 826-845.

[34] R. Ollitrault-Fichet, C. Gauthier, G. Clamen, P. Boch, Microstructural aspects in a polymer-modified cement, Cem. Concr. Res. 28 (1998) 1687-1693.

[35] R. Rixom, N. Mailvaganam, Chemical Admixtures for Concrete, E \& FN Spon, London, 1999.

[36] O. Rozenbaum, R.J.-M. Pellenq, H. Van Damme, An experimental and mesoscopic lattice simulation study of styrene-butadiene latex-cement composites properties, Mater. Struct. 38 (2005) 467-478.

[37] Y. Ohama, K. Demura, T. Endo, Properties of polymer-modified mortars using epoxy resin without hardener, in: L.A. Kuhmann, D.G. Walters (Eds.), Polymer-Modified Hydraulic-Cement Mixtures, STP 1176, ASTM, Philadelphia, 1993, pp. 90-103.

[38] Y.K. Jo, Basic properties of epoxy cement mortars without hardener after outdoor exposure, Constr. Build. Mater. 22 (2008) 911-920.

[39] M.A.R. Bhutta, K. Imamoto, Y. Ohama, Air permeability of hardener-free epoxymodified mortars as repair materials, in: M.G. Alexander, H.-D. Beushausen, F. Dehn, P. Moyo (Eds.), Concrete Repair, Rehabilitation and Retrofitting II, Taylor \& Francis Group, London, 2009, pp. 895-899.

[40] Y. Ohama, K. Demura, T. Katsuhata, Investigation of microcracks self-repair function of polymer-modified mortars using epoxy resins without hardener, in: D. Fowler (Ed.), Proceedings of the 10th International Congress on Polymers in Concrete, Honolulu, 2001, (CD-ROM). 